\title{
Biyopsisi Öncesinde Benign ve Malign Patolojileri Ayırmada Nötrofil Lenfosit Oranı, Trombosit Lenfosit Oranı ve Kırmızı Hücre Dağılım Genişiliği Parametreleri Kullanılabilir Mi?
}

Can Neutrophil Lymphocyte Ratio, Platelet Lymphocyte Ratio and Red Cell Distribution Width Parameters Be Used to Differentiate Benign and Malignant Pathologies Before Prostate Biopsy?

Afyonkarahisar Sağllk Bilimleri

Üniversitesi, Tip fakültesi Üroloji Anabilim Dal, Afyonkarahisar, Türkiye
Correspondence:

Abdullah GÜREL

Afyonkarahisar Sağlık Bilimleri

Üniversitesi, Tip fakültesi Üroloji Anabilim Dalı, Afyonkarahisar, Türkiye

e-mail: abdullahgurel@hotmail.com

\section{Özet}

Nötrofil lenfosit oranı (NLR), trombosit lenfosit oranı (PLR) ve kırmızı hücre dağılım genişliği (RDW) inflamatuar hastalıklar ve kanserler için önemli bir belirteçtir. Çalışmamızda NLR, PLR, RDW’nin prostat biyopsi kararı almada belirleyici olup olmadığ değerlendirildi. 2017 Mayıs ile 2019 Aralık tarihleri arasında prostat spesifik antijen (PSA) yüksekliği olması veya prostat muayenesinde bulgular olması nedeniyle transrektal ultrasonografi (TRUS) eşliğinde prostat biyopsisi yapılan hastaların patoloji sonuçları ve labaratuvar değerleri retrospektif olarak incelendi. Kontrol grubu olarak prostatla ilgili şikayeti olmayan ve inflamatuar hastalık öyküsü ve kanser tanısı olmayan kişiler alındı. Biyopsi sonucu benign ve prostat kanseri (Pca) gelen hastalar ve kontrol grubu arasında NLR, PLR ve RDW açısından farklılık olup olmadığı incelendi. Biyopsi yapılan hastalar benign ve Pca olarak karșlaștırıldığında; prostat spesifik antijen (PSA) ve yașın Pca grubunda istatistiksel olarak yüksek olduğu, hemoglobin değerinin ise düşük olduğu görüldü. NLR, PLR ve RDW açısından gruplar arasında farklılık olmadığı görüldü. Kontrol grubu ile Pca grubu karşılaştırıldığında NLR ve RDW değerlerinin Pca grubunda istatistiksel olarak daha yüksek olduğu görüldü. Prostat biyopsisi yapılan hastalarda Pca veya benign nedenlere bağlı inflamatuar bir durum mevcuttur. İnflamatuar belirteçler olan NLR, PLR ve RDW 'nin prostat biyopsisi öncesinde Pca ve benign ayrımı açısından belirteç olarak kullanılamayacağı saptandı. Kontrol grubu ile Pca arasında olan farkın ise kansere bağlı meydana gelen inflamasyona bağlı olduğu düşünüldü.

Anahtar Kelimeler: Prostat biyopsi, NLR, PLR, RDW, İnflamatuar biyomarker

\section{Abstract}

Neutrophil-lymphocyte ratio (NLR), platelet-lymphocyte ratio (PLR) and red cell distribution width (RDW) are important markers for inflammatory diseases and cancers. In our study, it was evaluated whether NLR, PLR, RDW were determinative for prostate biopsy decision. The pathology results and laboratory values of the patients who underwent transrectal ultrasonography (TRUS)-guided prostate biopsy between May 2017 and December 2019 due to elevated prostate specific antigen (PSA) or findings in prostate examination were analyzed retrospectively. People who had no prostate-related complaints, cancer diagnosis and no history of inflammatory disease were included as the control group. It was investigated whether there was a difference in NLR, PLR and RDW between the patients with benign prostate cancer (Pca) biopsy and the control group. When the biopsy patients were compared as benign and PCa; Prostate specific antigen (PSA) and age were found to be statistically higher in the Pca group, while the hemoglobin value was lower. There was no difference between the groups in terms of NLR, PLR and RDW. When the control group and the Pca group were compared, it was observed that the NLR and RDW values were statistically higher in the Pca group. Patients who underwent prostate biopsy have an inflammatory condition due to PCa or benign causes. It was determined that NLR, PLR and RDW, which are inflammatory markers, cannot be used as markers for the differentiation of PCa and benign before prostate biopsy. The difference between the control group and PCa was thought to be due to cancer-related inflammation.

Keywords: Prostate biopsy, NLR, PLR, RDW, Inflammatory biomarker 


\section{Giriş}

Prostat kanseri (Pca) yıllık 1.3 milyon yeni vaka ve 359.000 ölümle, dünya çapında erkeklerde akciğer kanserinden sonra en s1k görülen ikinci kanser ve kansere bağlı ölümlerin beşinci nedenini oluşturmaktadır(1). Lokalize Pca asemptomatiktir. Hastalı̆̆ın ilerleyen dönemlerinde metastaza bağl1 semptomlar ortaya çıkmaktadır. 1970'lerde tanımlanan prostat spesifik antijenin (PSA) keşfi ile hastalık asemptomatik dönemde tarama ile erken tanı konulabilecek bir hastalık olma özelliğini kazanmıştır(2). Tarama testi olarak PSA'nın yaygın olarak kullanılmasına rağmen halen çoğu Pca teşhisi semptomatik dönemde yapılmaktadır (3). Dijital rektal muayenede (DRM) malignite düşündüren bulguların olması ve PSA taramasında anormal sonuçların saptanması sonrasinda transrektal ultrasonografi (TRUS) kılavuzluğunda biyopsi yapılmas önerilmektedir(4). Prostat biyopsisinde TRUS eşliğinde yalnızca şüpheli alanlardan değil, prostatın tümünden farklı alanlarda biyopsi alınmaktadır (5). TRUS eşliğinde yapılan prostat biyopsisi ile Pca'de \%45'e varan tan artışı olmuştur(6). Bu durumun düşük hacimli ve yavaş ilerleyen hastaların aşırı tedavisine yol açtığ gösterilmiştir(7). Ek olarak TRUS kılavuzluğunda yapılan biyopside, \%30 oranında klinik olarak anlamlı prostat kanseri tanısının atlandığ 1 görülmüştür(8). Rutin olarak kullanılan TRUS eşliğinde uygulanan 12 kadran prostat biyopsisi önemli oranda Pca'nin tespit edilememesi ve klinik olarak önemsiz Pca'nin aşırı tanı almasının önüne geçilebilmesi için yeni arayışlar ortaya çıkmıştır. Multiparametrik manyetik rezonans görüntüleme (mpMRI) klavuzluğunda yapılan şüpheli alanlara yönelik yapılan prostat biyopsisi bu konuda son dönemde alternatif olmaya başlamıştır (9). Biyopsi öncesi Pca ile benign prostat hiperplazisi (BPH) ve prostatit gibi benign patolojileri ayıracak markerlara ihtiyaç duyulmaktadır. Tüm kanser vakalarının yaklaşık \%20'sinde kronik inflamasyon ve kronik infeksiyonun sorumlu olduğu bulunmuştur (10). Prostat kanseri patogenezinde ve progresyonunda inflamatuar süreçlerin önemli bir rolü olduğu gösterilmiştir (11, 12). İnflamatuvar markerlardan olan nötrofil lenfosit oranının (NLR) Pca'da kötü prognozu öngörmede kullanılabileceği bildirilmiştir (13). Trombosit lenfosit oranının (PLR) Pca de hastalıksız sağ kalım ve ortalama sağ kalımı öngörmede kullanılabileceği bildirilmiştir(14). Benzer şekilde kırmızı hücre dağılım genişliğinin (RDW) Pca'ni öngörmede (15) ve Pca progresyonunu öngörmede kullanılabilecek bir marker olduğu bildirilmiştir (16). Sciarra ve ark. tarafindan yapilan derlemede inflamatuar markerların Pca gelişiminde rol oynayabileceğinin, Pca progresyonunda ve radikal prostatektomi, radyoterapi ve hormonoterapi gibi tedavilere cevapta etkili olabileceği bildirilmekle birlikte, inflamatuar markerların sadece Pca spesifik olmadığının göz önünde bulundurulması gerekliliği belirtilmiştir (17). İnflamatuar markerların benign prostat hiperplazisi (BPH) ve prostatit gibi benign prostat hastalıklarında arttığ 1 bilinmektedir(18). Çalışmamızda TRUS eşliğinde biyopsi yapılan hastalarda inflamatuar markerların benign ve malign patolojileri öngörmede kullanılabilirliğinin değerlendirilmesi amaçland.

\section{Gereç ve Yöntemler}

Yozgat Bozok Üniversitesi Hastanesi Üroloji Kliniği'nde Mayıs 2017 ile Aralık 2019 tarihleri arasında PSA yüksekliği veya DRM'de bulgular olmasi nedeniyle TRUS eşliğinde prostat biyopsisi yapılan hastaların patoloji sonuçları ve labaratuvar değerleri retrospektif olarak incelendi. PSA, tam kan sayımindan elde edilen hemoglobin, RDW ve lenfosit, trombosit, nötrofil değerleri kullanılarak hesaplanan NLR ve PLR değerleri kayıt altına alındı Kanama bozukluğu öyküsü olan, hematolojik rahatsızlık tanisı olan, kan parametrelerini değiştiren ilaç kullanan, inflamatuvar hastalık öyküsü olan, farklı bir kanser tanısı olan ve dosya bilgilerinde eksiklik olan hastalar çalışmaya dahil edilmedi. Hastalar biyopsi sonucuna göre benign ve malign (Pca) olarak iki gruba ayrıld1. Kontrol grubu olarak prostat ile ilgili şikayeti olmayan ve prostat ile ilgili ilaç kullanmayan, PSA seviyeleri $4 \mathrm{ng} / \mathrm{ml}$ altında olan, infalamatuvar hastalığ bulunmayan, kanama bozukluğu öyküsü olmayan, daha önce hematolojik rahatsızlık ve malignite tanısı almamış başka nedenlerle 
üroloji kliniğine bașvuran sağllklı erkekler alınd. Prostat biyopsisi yapılan ve patoloji sonucu benign gelen 133 (\%38), patoloji sonucu Pca gelen $59(\% 16.86)$ ve kontrol grubu olarak $158 \quad(\% 45.14)$ toplam 350 hastanın verileri incelendi. Patoloji sonucu Pca saptanan hastalar, benign saptanan hastalar ve kontrol grubu arasında yaş, PSA değeri, hemoglobin değeri, RDW, NLR, PLR açısından farklılık olup olmadığı incelendi. TRUS biyopsi yapilan hastalar PSA değerlerine göre 0-3.99 $\mathrm{ng} / \mathrm{ml}$ olanlar grup 1, 4-9.99 ng/ml olanlar grup 2, 10-19.99 ng/ml olanlar grup 3 ve $20 \mathrm{ng} / \mathrm{ml}$ üzerinde olanlar grup 4 olarak tanımlandi. Gruplar arasında biyopsi patolojileri, NLR, PLR, RDW açısından farklılık olup olmadığ 1 karşılaştırıld1.

\section{Etik Onay}

Çalışma için Yozgat Bozok Üniversitesi Klinik Araştırmalar Etik kurulu 2017-KAEK189_2019.02.28_19 sayıl1 etik kurul onay1 alındi.

\section{İstatistiksel Analiz}

Çalışma verilerinin istatistiksel analizi IBM SPSS(Statistical Package for the Social Sciences) version 15.0 programı ile yapıldı. Değișkenlerin normal dağılıma uygunluğu Kolmogorow-Smirnov testi kullanılarak incelendi. Üçlü grupların karşıllaştııılmasında Kruskal-Wallis testi, ikili grupların karşılaştırılmasında Mann-Whitney U testi kullanıldı. PSA ile NLR, PLR, RDW'nin korelasyonunda Spearman testi uygulandi. Prostat kanseri varlığını öngörmede NLR, PLR, RDW'nin tanısal karar verdirici özelliği olup olmadığ 1 Receiver Operating Characteristics (ROC) eğrisi analizi ile yapıldı. $\mathrm{P}$ değeri $<0,05$ olduğunda sonuçlar anlamlı olarak kabul edildi.

\section{Bulgular}

Hastaların yaş ortalaması kontrol grubunda $65.31 \pm 5.48 \quad(55-83) \quad$ y1l, benign grupta $63.68 \pm 6.87 \quad(46-84) \quad$ y11, malign grupta
$67.49 \pm 6.68$ (50-84) y1l olarak hesapland1. Gruplar kendi aralarında karşılaştırıldığında, kontrol ile benign grup $(\mathrm{p}=0.071)$ ve kontrol ile malign grup $(\mathrm{p}=0.059)$ arasinda istatistiksel farkl1l1k saptanmadı. Benign ve malign grup arasında istatistiksel olarak fark olduğu görüldü $(p<0.001)$. PSA değerleri kontrol grubunda $2.36 \pm 1.00(0.65-3.97) \mathrm{ng} / \mathrm{ml}$, benign grupta $7.75 \pm 5.72(2.00-42.37) \mathrm{ng} / \mathrm{ml}$, malign grupta $55.77 \pm 190.40 \quad(3.16-1454.00) \quad \mathrm{ng} / \mathrm{ml}$ olarak hesaplandı. Gruplar kendi aralarında karşılaştırıldığında, gruplar arasında istatistiksel olarak anlaml 1 fark saptand $1(p<0.001)$. Hemoglobin değeri ortalamalar1 kontrol grubunda 16.88 \pm 9.20 $\mathrm{gr} / \mathrm{dl}$, benign grupta $15.10 \pm 1.49 \mathrm{gr} / \mathrm{dl}$, malign grupta $14.28 \pm 1.80 \mathrm{gr} / \mathrm{dl}$ olarak hesapland. Gruplar kendi aralarında karşılaştırıldığında kontrol ile benign grup $(\mathrm{p}<0.001)$, kontrol ile malign grup $(\mathrm{p}<0.001)$ ve benign ile malign grup $(p=0.003)$ arasında istatistiksel olarak farkl111k olduğu görüldü. NLR ortalamas1 kontrol grubunda $1.93 \pm 0.62$, benign grupta $2.83 \pm 2.59$, malign grupta $2.75 \pm 1.66$ olarak hesaplandi. Gruplar kendi aralarında karşılaştırıldığında kontrol ile benign grup arasinda fark olduğu $(\mathrm{p}<0.001)$, kotrol ile malign grup arasında fark olduğu $(\mathrm{p}=0.008)$, benign ve malign grup arasında fark olmadiğ 1 ( $p=0.96)$ görüldü. PLR ortalaması kontrol grubunda $113.15 \pm 32.73$, benign grupta $128.16 \pm 72.80$, malign grupta $123.55 \pm 46.34$ olarak hesaplandı. Gruplar kendi aralarında karşılaştırıldığında kontrol ile benign grup arasında farklılık olduğu $(\mathrm{p}=0.046)$, kontrol ile malign grup arasında fark olmadiğ 1 $(p=0.410)$ ve benign ve malign grup arasında fark olmadığ1 $(\mathrm{p}=0.846)$ görüldü. RDW değeri ortalamalar1 kontrol grubunda $12.63 \pm 0.81$, benign grupta $13.54 \pm 1.40$, malign grupta 13.98. \pm 1.60 olarak hesapland1. Gruplar kendi aralarında karşılaştırıldığında kontrol ile benign grup $(\mathrm{p}<0.001)$ ve kontol ile malign grup $(\mathrm{p}<0.001)$ arasında istatistiksel olarak fark olduğu görüldü. Benign ve malign grup arasında farklılık olmadığ 1 görüldü $(\mathrm{p}=0.156)$. Tablo 1 de çalışmaya alınan hastaların gruplara göre karşılaştırılması verilmiştir. 
Tablo1. Çalışmaya alınan hastaların gruplara göre karşılaştırılması

\begin{tabular}{lllll}
\hline & Kontrol & Benign & Malign & P \\
\hline Yaş & $65.31 \pm 5.48$ & $63.68 \pm 6.87$ & $67.49 \pm 6.68$ & $\mathbf{p}<\mathbf{0 . 0 0 1}$ \\
& $(55-83)$ & $(46-84)$ & $(50-84)$ & \\
PSA(ng/ml) & $2.36 \pm 1.00$ & $7.75 \pm 5.72$ & $55.77 \pm 190.40$ & $\mathbf{p}<\mathbf{0 . 0 0 1}$ \\
& $(0.65-3.97)$ & $(2.00-42.37)$ & $(3.16 \pm 1454.00)$ & \\
Hemoglobin & $16.88 \pm 9.20$ & $15.10 \pm 1.49$ & $14.28 \pm 1.80$ & $\mathbf{p}<\mathbf{0 . 0 0 1}$ \\
(gr/dl) & & & & \\
NLR & $1.93 \pm 0.62$ & $2.83 \pm 2.59$ & $2.75 \pm 1.66$ & $\mathbf{p}<\mathbf{0 . 0 0 1}$ \\
PLR & $113.15 \pm 32.73$ & $128.16 \pm 72.80$ & $123.55 \pm 46.34$ & $\mathbf{p}=0.238$ \\
RDW (\%) & $12.63 \pm 0.81$ & $13.54 \pm 1.40$ & $13.98 \pm 1.60$ & $\mathbf{p}<\mathbf{0 . 0 0 1}$ \\
Hasta sayısı & $158(\% 45.14)$ & $133(\% 38)$ & $59(\% 16.86)$ & \\
\hline
\end{tabular}

Biyopsi yapılan hasta grubu incelendiğinde; PSA ile NLR $(\mathrm{p}=0.048, \mathrm{r}=0.14)$ ve PLR $(\mathrm{p}=0.046, \mathrm{r}=0.14)$ arasında düşük düzeyde korelasyon olduğu görüldü. PSA ile RDW arasında korelasyon olmadığ 1 görüldü $(\mathrm{p}=0.26, \mathrm{r}=0.081)$. Roc analizi yapilarak NLR, PLR ve RDW parametreleri incelendi. Parametrelere ait eğrilerin birbiriyle benzer ve orta hatta dağılım gösterdiği görüldü. AUC değeri NLR için 0.527, PLR için 0.503, RDW için 0.564 olarak hesaplandi. $(\mathrm{p}>0.005)$ Şekil 1 de PSA ile NLR, PLR, RDW arasindaki ROC analizi gösterilmektedir.

Prostat biyopsisi yapilan hastalar PSA değerleri açısından gruplara ayrıldığında;
Grup1 de (0-3.99 ng/ml) 15(\%7.8), grup 2 de (4-9.99 ng/ml) $112(\% 58.3)$, grup 3 de (10$19.99 \mathrm{ng} / \mathrm{ml}) \quad 36 \quad(\% 18.8)$, grup $4 \mathrm{de}$ $(>20 \mathrm{ng} / \mathrm{ml}) \quad 29 \quad(\% 15.1) \quad$ hastanın olduğu görüldü. PSA gruplarına göre PLR, NLR ve RDW değerleri açısından farklılık olup olmadığı incelendiğinde yalnızca grup 4 deki $(\mathrm{PSA}>20)$ hastalarda PLR değerinin $148.65 \pm 50.86$ olduğu ve diğer gruplardan istatistiksel olarak farklı olduğu görüldü $(\mathrm{p}=0.004)$. Gruplar arasinda NLR $(\mathrm{p}=0.081)$ ve $\operatorname{RDW}(\mathrm{p}=0.344)$ açısından istatistiksel olarak farklılık olmadığı görüldü. Tablo $2 \mathrm{de}$ biyopsi yapılan hastaların PSA gruplarına göre NLR; PLR ve RDW değerlerinin karşılaştırılması gösterilmektedir.

Tablo2. Biyopsi yapılan hastaların PSA gruplarına göre NLR; PLR ve RDW değerlerinin karşılaştırılması

\begin{tabular}{llllll}
\hline & Grup 1 & Grup 2 & Grup 3 & Grup 4 & P \\
\hline NLR & $2.21 \pm 0.95$ & $2.73 \pm 2.53$ & $2.63 \pm 1.69$ & $3.59 \pm 2.69$ & $\mathrm{p}=0.081$ \\
PLR & $115.54 \pm 29.22$ & $124.62 \pm 74.86$ & $119.71 \pm 54.28$ & $148.65 \pm 50.87$ & $\mathrm{p}=\mathbf{0 . 0 0 4}$ \\
RDW & $13.91 \pm 1.35$ & $14.67 \pm 1.76$ & $13.56 \pm 1.26$ & $14.17 \pm 1.90$ & $\mathrm{p}=0.344$ \\
Hasta sayısı & $15(\% 7.8)$ & $112(\% 58.3)$ & $36(\% 18.8)$ & $29(\% 15.1)$ & \\
\hline
\end{tabular}

Biyopsi sonucunda Pca tanisi alan hastaların gleason skoru ile NLR, PLR ve RDW açısından korelasyon analizi yapıldığında; gleason skoru ile NLR arasinda korelasyon olmadığ 1 görüldü $(\mathrm{p}=0.1)$. Gleason skoru ile PLR arasinda $(\mathrm{p}=0.024 \mathrm{r}=0.294)$ ve $\mathrm{RDW}$ arasinda $\quad(\mathrm{p}=0.002, \quad \mathrm{r}=0.396) \quad$ korelasyon olduğu görüldü.

\section{Tartışma ve Sonuç}

Pca erkeklerde sık görülen ve ölüme sebebiyet veren bir kanser türü olması nedenli önemli bir sağlı sorunu olmaya devam etmektedir. Günümüzde görüntüleme modalitelerindeki gelişmelere rağmen, TRUS rehberliğinde prostat biyopsisi halen $\mathrm{PCa}$ tanısinda altın standart olmaya devam etmektedir (19). Pca'de inflamatuar markerların sağlıklı kişlere göre yüksek olduğu ve Pca'de prognozda önemli olduğu yapılan çalışmalarda gösterilmiştir $(13,14,16)$. Çalışmamızda sağlıklı kişlere göre Pca olanlarda NLR ve RDW değerinin istatistiksel olarak anlamlı dercede yüksek olduğu görüldü. PLR'in ise sağlıklı kişlere göre Pca'de yüksek olduğu ancak istatistiksel olarak bu yüksekliğin anlamlı olmadığı görüldü. Sağlıklı kişlere göre Pca'de inflamatuar markerlarda oluşan yüksekliğin, kansere bağlı oluşan inflamasyon sonucu meydana geldiği düşünüldü. 
Literatür incelendiğinde prostat biyopsisi öncesi inflamatuar markerların kanseri öngörmede kullanılabilmesi açısından kısıtlı sayıda çalışma mevcuttur. Kawahara ve ark. çalışmalarında prostat biyopsisi yapılan hastalarda NLR'nin Pca grubunda benign gruba göre istatistiksel olarak yüksek olduğu ve NLR'nin biyopsi öncesi kullanılabilecek bir marker olduğunu bildirmişlerdir. PSA 20 $\mathrm{ng} / \mathrm{ml}$ değerine kadar NLR'nin değişmediği $20 \mathrm{ng} / \mathrm{ml}$ üzerindeki değerlerde NLR'nin PSA ile korele arttığını bulmuşlar. NLR'ın gleason skoru ile korelasyon göstermediğini belirtmişlerdir. (20). Yüksel ve ark. çalışmalarında biyopsi öncesi NLR'nın Pca ve BPH ayrımında kullanılabileceğini bildirmişlerdir. $\mathrm{Bu}$ çalışmada hastalar Pca, $\mathrm{BPH}$ ve prostatit şeklinde üç gruba ayrılmış. BPH ve Pca grupları arasında NLR değerleri açısından farklılık olduğu bildirilmiştir. NLR değerinin prostatit grubunda, Pca grubuna göre yüksek olduğu görülmüştür. (21). Mevcut çalışmada malign ve benign nedenler açısından karşılaştırma yapılsaydı farklılık görülmeyebilirdi diye düşünüyoruz Deniz ve ark. çalışmalarında NLR'nin PSA ile korele arttı̆̆ını, Pca'de BPH'ne göre istatistiksel olarak yüksek olduğunu bildirmişler ve Pca gelen gurupta NLR' in gleason skoru ile korele olarak arttığını bildirmişlerdir (22). Tanık ve ark. çalışmalarında NLR'nin BPH'de prognostik öneme sahip olduğunu ve BPH'de NLR'nın arttığını bildirmişlerdir (23). Çalışmamızda biyopsi yapılan hasta grubunda PSA ile NLR'in düşük düzeyde korelasyon gösterdiği görüldü. Benign patolojiler ve Pca karşılaştırıldığında NLR açısından istatistiksel olarak farklılık saptanmadi. PSA'yı artıran prostatit ve BPH gibi benign nedenler ve Pca gibi malign nedenlerde oluşan inflamasyona bağlı NLR'da artış olması bu durumu açıklamaktadır. Çalışmamızda Kawahara ve ark yaptıkları çalışmaya benzer olarak gleason skoru ile NLR arasında korelasyon olmadığ 1 görüldü.

Yüksel ve ark. çalışmalarında prostat biyopsisi yapılan hastalarda PLR'in Pca grubunda BPH grubuna göre yüksek olduğunu, prostatit grubuna göre ise düşük olduğunu bildirmişlerdir. (21). Mevcut çalışmada PLR açısından Pca grubu ve benign patolojiler açısından farklılık olmadığı görülmektedir. Çalışmamızda biyopsi yapılan hasta grubunda benign patolojiler ile Pca açısından PLR açısından farklılık olmadığı görüldü. Sun ve ark. çalışmalarında Pca'de PLR'nin gleason skoru ile korele arttı̆̆ını bildirmişlerdir (24). Çalışmamızda benzer şekilde PLR'nın gleason skoru ile korele arttığ1 görüldü.

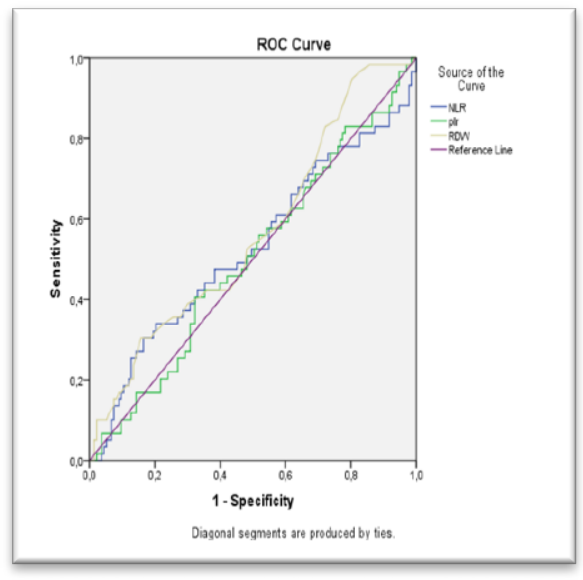

Şekil 1. NLR, PLR, RDW için ROC analizi

Huang ve ark. çalışmalarında prostat biyopsisi yapilan hastalarda Pca grubunda RDW değerinin benign gruba oranla yüksek olduğunu ve biyopsiyi öngörmede kullanılabilecek bir belirteç olduğunu belirtmişlerdir(15). Albayrak ve ark çalışmalarında RDW'nin Pca'de gleasom skoru ile korelasyon gösterdiği ve prognozda önemli olduğunu bildirmişlerdir (16). Sun ve ark. ise çalışmalarında Pca'de RDW'nin gleason skoru ile korelasyon göstermediğini bulmuşlardır (24). Çalışmamızda Pca ve benign patolojiler açısından RDW değerinde farklılık olmadığ 1 ancak Pca grubunda gleason skoru ile RDW arasında korelasyon olduğu görüldü.

Çalışmamızın kısıtlılıkları olarak retrospektif bir çalışma olması, Pca hasta sayısının az olması sayılabilir. Çalışmamızın prospektif daha fazla hasta içeren çalışmalarla desteklenmesi gerekmektedir.

NLR, PLR ve RDW gibi markerlar inflamasyonla seyreden malign ve benign hastalıklarda yükselmektedir. TRUS biyopsi yapilan hasta grubunda benign ve malign nedenler inflamasyonla seyreden hastaliklar arasında yer alması nedenli bu markerların 
biyopsi öncesi patolojiyi öngörmede kullanılamayacağını; ancak Pca'de meydana gelen inflamasyona bağlı olarak normal sağl1klı kişlere göre markerlarda yükseklik olması beklenen bir durum olmalıdır.

\section{KAYNAKLAR}

1. Bray F, Ferlay J, Soerjomataram I, et al. Global cancer statistics 2018: GLOBOCAN estimates of incidence and mortality worldwide for 36 cancers in 185 countries. CA: a cancer journal for clinicians. 2018;68:394-424.

2. Wang MC, Valenzuela LA, Murphy GP, et al. Purification of a human prostate specific antigen. Investigative urology. 1979;17:159-63.

3. National Collaborating Centre for C. National Institute for Health and Care Excellence: Clinical Guidelines. Suspected Cancer: Recognition and Referral. London: National Institute for Health and Care Excellence (NICE)

4. Hodge KK, McNeal JE, Stamey TA. Ultrasound guided transrectal core biopsies of the palpably abnormal prostate. J Urol. 1989;142:66-70.

5. Lomas DJ, Ahmed HU. All change in the prostate cancer diagnostic pathway. Nature reviews Clinical oncology. 2020;17:372-81.

6. Schröder FH, Hugosson J, Roobol MJ, et al. Screening and prostate-cancer mortality in a randomized European study. The New England journal of medicine. 2009;360:1320-8.

7. Loeb S, Bjurlin MA, et al. Overdiagnosis and overtreatment of prostate cancer. European urology. 2014;65:1046-55.

8. Serefoglu EC, Altinova S, Ugras NS, et al. How reliable is 12-core prostate biopsy procedure in the detection of prostate cancer? Canadian Urological Association journal $=$ Journal de l'Association des urologues du Canada. 2013;7:E293-8.

9. Kesch C, Schütz V, Dieffenbacher S, et al. Multiparametric MRI fusion-guided biopsy for the diagnosis of prostate cancer. Current opinion in urology. 2018;28:172-7.

10. Shacter E, Weitzman SA. Chronic inflammation and cancer. Oncology (Williston Park, NY). 2002;16:217-26, 29; discussion 30-2.

11. Sfanos KS, De Marzo AM. Prostate cancer and inflammation: the evidence. Histopathology. 2012;60:199-215.

12. Haverkamp J, Charbonneau B, Ratliff TL. Prostate inflammation and its potential impact on prostate cancer: a current review. Journal of cellular biochemistry. 2008;103:1344-53.

13. Gu X, Gao X, Li X, et al. Prognostic significance of neutrophil-to-lymphocyte ratio in prostate cancer: evidence from 16,266 patients. Scientific reports. 2016;6:22089.

14. Wang J, Zhou X, He Y, et al. Prognostic role of platelet to lymphocyte ratio in prostate cancer: A meta-analysis. Medicine (Baltimore). 2018;97:e12504.

15. Huang TB, Zhu LY, Zhou GC, et al. Pre-treatment red blood cell distribution width as a predictor of clinically significant prostate cancer. International urology and nephrology. 2021;53:1765-71.

16. Albayrak S, Zengin $\mathrm{K}$, Tanik S, et al . Red cell distribution width as a predictor of prostate cancer progression. Asian Pacific journal of cancer prevention : APJCP. 2014;15:7781-4.

17. Sciarra A, Gentilucci A, Salciccia $S$, et al. Prognostic value of inflammation in prostate cancer progression and response to therapeutic: a critical review. Journal of inflammation (London, England). 2016;13:35

18. Bardan R, Dumache R, Dema A, et al. The role of prostatic inflammation biomarkers in the diagnosis of prostate diseases. Clinical biochemistry. 2014;47:909-15.

19. Omer A, Lamb AD. Optimizing prostate biopsy techniques. Current opinion in urology. 2019;29:578-86.

20. Kawahara T, Fukui S, Sakamaki K, et al. Neutrophil-to-lymphocyte ratio predicts prostatic carcinoma in men undergoing needle biopsy. Oncotarget. 2015;6:32169-76.

21. Yuksel OH, Urkmez A, Akan S, et al. Predictive Value of the Platelet-To-Lymphocyte Ratio in Diagnosis of Prostate Cancer. Asian Pacific journal of cancer prevention : APJCP. 2015;16:6407-12.

22. Deniz ME, Erçil H, Alma E, et al. Prostat Kanseri Tanısında Kan Nötrofil/Lenfosit Dağılımının Yeri. The New Journal of Urology 2020; 15: 66-74.

23. Tanik S, Albayrak S, Zengin $\mathrm{K}$, et al. Is the neutrophil-lymphocyte ratio an indicator of progression in patients with benign prostatic hyperplasia? Asian Pacific journal of cancer prevention : APJCP. 2014;15:6375-9.

24. Sun Z, Ju Y, Han F, et al. Clinical implications of pretreatment inflammatory biomarkers as independent prognostic indicators in prostate cancer. Journal of clinical laboratory analysis. 2018;32. 